\title{
Die Zeit der Alten
}

\section{Hans Stalder}

Prof. Dr. med., Redaktionsmitglied

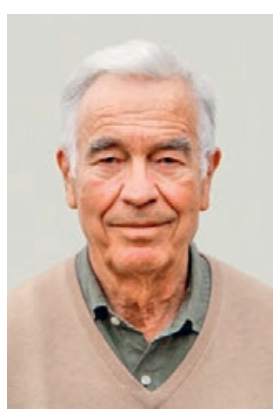

Was also ist die Zeit? Wenn niemand mich danach fragt, weiss ich's, will ich's aber einem Fragenden erklären, weiss ich's nicht.

(Augustinus)

Schon lang ist's her - ich war noch berufstätig -, dass Professor Charles-Henri Rapin und ich bei einer Sitzung uns die Frage stellten, wie ältere Menschen wohl die Zeit empfänden. Wenn wir sie beobachteten, hatten wir das Gefühl, dass es sich von dem der Jungen, zu denen wir damals zählten, unterscheiden dürfte.

Nun, da ich selbst alt bin, werde ich versuchen, meine Eindrücke zu schildern. Eines ist sicher: Die Zeit vergeht immer schneller. Dafür gibt es eine Erklärung: Wenn ein Kind seinen zweiten Geburtstag feiert, ist es doppelt so alt wie bei seinem ersten. Zwischen dem zehnten und dem elften Geburtstag kommt nur noch ein Zehntel hinzu. Und zwischen dem achtzigsten und dem einundachtzigsten? Gerade mal ein Achtzigstel! Was im Verhältnis zu unserer bisherigen Lebenszeit noch vor uns liegt, nimmt also nicht linear, sondern exponentiell ab. Diese Überlegung ist in Zeiten knapper Gesundheitsressourcen, wie wir sie während der COVID-19-Epidemie erleben mussten, wichtig. Alle sind sich einig, dass die zur Verfügung stehenden Ressourcen ohne Diskriminierung aufgrund von Geschlecht, Wohnort, Nationalität, religiöser Zugehörigkeit, sozialer Stellung und Versicherungsstatus zu verteilen sind [1]. Aber wie verhält es sich mit dem Alter? Ist die Verlängerung des Lebens eines jungen Menschen um ein Jahr, zum Beispiel von 40 auf 41 Jahre, nicht mehr wert als ein zusätzliches Lebensjahr für einen 80-Jährigen, selbst wenn dieser bei bester Gesundheit ist? Ein anderer Aspekt, den es gerade für junge Menschen zu verstehen gilt, ist, dass sehr alte Menschen sich mitunter Beistand wünschen, um sich jene allerletzte Zeit des Lebens zu ersparen, falls sie unerträglich leiden sollten.

Während die Zeit also immer schneller vergeht, ist es paradox, dass alles mehr Zeit braucht. Wenn ich vermeintlich wirklich schnell unterwegs bin, kann es passieren, dass ich von einer jungen Frau überholt werde, die gar nicht in Eile zu sein scheint. Eine alte Dame gestand mir einmal, kaum sei sie aufgestanden, habe sich gewaschen, angezogen und gefrühstückt, müsse sie bereits das Mittagessen vorbereiten ... Aber glücklicherweise haben wir als Rentner dennoch mehr Zeit - ein weiteres Paradoxon! Zeit kann linear oder kreisförmig erlebt werden. Die lineare Vorstellung von Zeit gründet auf dem Erwarten: So empfinden junge Menschen die Zeit. Man bangt auf den ersten Schultag, ersehnt den Ferienbeginn, den Abschluss der Ausbildung, die Heirat, die Kinder, den Ruhestand. Und dann? Natürlich hegen auch Rentner noch Pläne, aber irgendwann wird es sich bei der nächsten Etappe um das Ende handeln. Selbst im Alter ist es nicht leicht, dem Tod ins Auge zu blicken ... Deshalb nehmen alte Menschen die Zeit lieber kreisförmig wahr. Als Wiederholung. Jeden Morgen stehen wir zur gleichen Zeit auf, jeden Nachmittag machen wir ein Nickerchen, dann einen Spaziergang; später freuen wir uns auf die Abendnachrichten, im Frühling stellen wir die Blumen auf den Balkon, jedes Jahr feiern wir die Geburtstage unserer Lieben. Diese immer wiederkehrenden Handlungen können uns unsere Ängste nehmen, aber auch zwanghaft werden, gerade wenn Gedächtnislücken ins Spiel kommen: Habe ich heute Abend schon die Tür abgesperrt? Das erklärt auch, warum alte Menschen nicht gerne auf ihre Gewohnheiten verzichten: Denn gerade in ungewohnten Situationen wird die Zeit wieder linear und beängstigend, bis die neue Situation vertraut geworden ist.

Und trotz allem erleben alte Menschen glückliche Momente! Dann nämlich, wenn die Zeit stillzustehen scheint, was die Psychoanalytikerin Danielle Quinodoz als «Sekunden Ewigkeit» [2] beschrieben hat. Es sind diese Momente - hervorgerufen durch den Gesang eines Vogels, einen Blick, ein Gedicht, ein Gemälde -, die die Zeit anhalten und sie vergessen machen.

Ich weiss, dass schon viele andere - Dichter, Künstler, Philosophen, Physiker - über dieses Thema weitaus tiefer nachgedacht haben [3]. Ausserdem hätte ich diesem Text wohl besser nicht den Titel «Die Zeit der Alten» voranstellen sollen, sondern vielmehr «Die Zeit eines Alten", denn im Gespräch mit anderen Senioren habe ich festgestellt, dass sie meine Meinung durchaus nicht immer teilen. Wenn Sie, meine lieben älteren Kolleginnen und Kollegen, die Zeit ebenfalls anders wahrnehmen, dann freut sich die Redaktion auf Ihren Leserbrief!

\section{Literatur}

1 Covid-19-Pandemie: Triage von intensivmedizinischen Behandlungen bei Ressourcenknappheit. Hinweise zur Umsetzung (2013) > samw.ch

2 Quinodoz Danielle. Älterwerden - Eine Entdeckungsreise. Giessen: Psychosozial-Verlag; 2008.

3 lemysteredutemps.wordpress.com 